\title{
Taxonomic revision of the Nippostrongylinae (Nematoda, Heligmonellidae) parasites of Muridae from the Australasian region. The genus Odilia Durette-Desset, 1973
}

\author{
Marie-Claude Durette-Desset ${ }^{1,{ }^{*}}$ and María Celina Digiani ${ }^{2,3}$ \\ 1 ISYEB, Institut Systématique, Évolution, Biodiversité, UMR7205 CNRS, EPHE, MNHN, UPMC, \\ Muséum National d'Histoire Naturelle, Sorbonne Universités, 61 rue Buffon, 75231 Paris Cedex 05, France \\ 2 CONICET-Consejo Nacional de Investigaciones Científicas y Técnicas, Argentina \\ 3 División Zoología Invertebrados, Facultad de Ciencias Naturales y Museo, Universidad Nacional de La Plata, \\ Paseo del Bosque s/n, 1900 La Plata, Argentina
}

Received 29 June 2015, Accepted 14 October 2015, Published online 23 November 2015

\begin{abstract}
The species of the genus Odilia Durette-Desset, 1973 (Heligmonellidae, Nippostrongylinae) are re-distributed among eight genera of which five are new. This classification is mainly based on certain characters of the synlophe not previously taken into account at the supraspecific level. These characters mainly include the presence or absence of a careen, the relative size of the ridges forming the careen, the development and position of ridge 1', the development of the left ridge and right ridge, and the distribution of the largest ridges. Eighteen of the 20 known species are rearranged in the following genera: Odilia sensu stricto Durette-Desset, 1973 with Odilia mackerrasae (Mawson, 1961) as type species, Chisholmia n. gen. with Chisholmia bainae (Beveridge \& Durette-Desset, 1992) n. comb. as type species, Equilophos n. gen. with Equilophos polyrhabdote (Mawson, 1961) n. comb. as type species, Hasegawanema n. gen. with Hasegawanema mamasaense (Hasegawa, Miyata \& Syafruddin, 1999) n. comb. as type species, Hughjonestrongylus Digiani \& Durette-Desset, 2014 with Hughjonestrongylus ennisae (Smales \& Heinrich, 2010) as type species, Lesleyella $\mathrm{n}$. gen. with Lesleyella wauensis (Smales, 2010) n. comb. as type and sole species, Parasabanema szalayi Smales \& Heinrich, 2010, and Sanduanensis n. gen. with Sanduanensis dividua (Smales, 2010) as type and sole species. Odilia uromyos Mawson, 1961 and Odilia carinatae Smales, 2008 are not included in the new classification. A key to the proposed genera is provided. The new generic arrangement follows a distribution more related to the biogeographical areas than to the host groups.
\end{abstract}

Key words: Trichostrongylina, Synlophe, New genera, Australia, Indonesia, New Guinea.

Résumé - Révision taxonomique des Nippostrongylinae (Nematoda, Heligmonellidae) parasites de Muridae de la région australasienne. Le genre Odilia Durette-Desset, 1973. Les espèces du genre Odilia Durette-Desset, 1973 (Heligmonellidae, Nippostrongylinae) sont réparties en huit genres, dont cinq nouveaux. Cette classification s'appuie principalement sur certains caractères du synlophe non pris en compte jusqu'à présent au niveau supraspécifique. Ces caractères incluent principalement la présence ou l'absence d'une carène, la taille relative des crêtes formant la carène, le développement et la position de la crête 1', le développement de la crête gauche et de la crête droite, et la répartition des crêtes les plus larges. Dix-huit espèces sur les 20 actuellement connues sont classées dans les genres suivants: Odilia sensu stricto Durette-Desset, 1973 avec Odilia mackerrasae (Mawson, 1961) comme espèce type, Chisholmia n. gen. avec Chisholmia bainae (Beveridge \& Durette-Desset, 1992) n. comb. comme espèce type, Equilophos n. gen. avec Equilophos polyrhabdote (Mawson, 1961) n. comb. comme espèce type, Hasegawanema n. gen. avec Hasegawanema mamasaense (Hasegawa, Miyata \& Syafruddin, 1999) n. comb. comme espèce type, Hughjonestrongylus Digiani \& Durette-Desset, 2014 avec Hughjonestrongylus ennisae (Smales \& Heinrich, 2010) comme espèce type, Lesleyella n. gen. avec Lesleyella wauensis (Smales, 2010) n. comb. comme espèce type et unique espèce, Parasabanema szalayi Smales \& Heinrich, 2010 et Sanduanensis n. gen. avec

\footnotetext{
*Corresponding author: medd@mnhn.fr

Marie-Claude Durette-Desset - urn:1sid:zoobank.org:author:CE1DED20-9732-4AA8-A835-E2EAA6061826

María Celina Digiani - urn:lsid:zoobank.org:author:B1772073-B854-45E0-96E8-D9505E993E23
}

This is an Open Access article distributed under the terms of the Creative Commons Attribution License (http://creativecommons.org/licenses/by/4.0), which permits unrestricted use, distribution, and reproduction in any medium, provided the original work is properly cited. 


\begin{abstract}
Sanduanensis dividua (Smales, 2010) comme espèce type et unique espèce. Odilia uromyos Mawson, 1961 et Odilia carinatae Smales, 2008 ne sont pas incluses dans la nouvelle classification. Une clé dichotomique des genres proposés est fournie. Le nouvel arrangement générique suit une répartition plus liée aux aires biogéographiques qu'aux groupes d'hôtes.
\end{abstract}

\section{Introduction}

This paper contains a taxonomic revision of the Australasian Nippostrongylinae. In a preceding paper, we studied the Paraheligmonelloides complex, which was divided into four genera [4]. The present paper concerns the genus Odilia Durette-Desset, 1973, with 20 described species in murids from mainland Australia, Tasmania, Borneo, Sulawesi, and New Guinea.

Durette-Desset [6] created the nematode genus Austrostrongylus to include the following species parasitic in Australian Muridae: Heligmonoides mackerrasae Mawson, 1961 (type species), Longistriata brachybursa Mawson, 1961, Heligmonoides emanuelae Mawson, 1961, Heligmonoides mawsonae Durette-Desset, 1969, Longistriata melomyos Mawson, 1961, Longistriata polyrhabdote Mawson, 1961, and Longistriata uromyos Mawson, 1961 [17]. As the name Austrostrongylus was preoccupied, created by Chandler [2] for nematode parasites of Australian marsupials, with $A$. macropodis as type species, Durette-Desset [7] proposed the new name Odilia for the parasites of Australian Muridae. Probably by omission, the species brachybursa was not included in the new combinations with Odilia.

The synlophe of these species (except O. uromyos) was described by Durette-Desset [5] and the genus Odilia (=Austrostrongylus sensu Durette-Desset, 1971, nec Chandler, 1924) was defined as follows: "synlophe with axis of orientation directed from right-ventral line to left-dorsal line; hypertrophied lateral ridges; left-dorsal ridge almost as long as left-ventral ridge tending to the formation of a small careen, the latter remaining of moderate size. Gradient in ridge size lateromedian or ridges very numerous and of similar size" [6].

After a gap of approximately 20 years, eight new species were described between 1992 and 2005: three from mainland Australia and Tasmania [1, 11], and five from Indonesia [12, 16]. Smales [20] proposed a key to the 15 species then known in the genus, mainly based on the number of cuticular ridges and, to a lesser extent, on the length of the gubernaculum. Since 2005, five other species from New Guinea have been described and assigned to Odilia [21-23, 25], bringing the number of species in the genus to 20 .

At present, the composition of the genus is very heterogeneous, mainly due to the great variability of the synlophe among the species: some species possess a careen, whereas other species do not, the number of ridges varies from 14 to 35 , the lateral ridges are not always well developed, and the ridge size also varies considerably.

It is likely, in one way, that the generic definition was sufficiently ambiguous to allow the inclusion of species with very different synlophes. In another way, however, some species do not even match the generic definition.

In an ongoing revision of the Heligmonellidae, it became necessary to review the specific composition of Odilia, and to attempt to group the species into new, possibly supraspecific taxa. This work is presented here, based mainly on the morphology of the synlophe, a complex structure involving numerous characters, some of which are proving to be taxonomically useful at the supraspecific level.

\section{Materials and methods}

The data were compiled from the published descriptions. The species whose synlophe could be analyzed were: Odilia mackerrasae (Mawson, 1961), Odilia bainae Beveridge \& Durette-Desset, 1992, Odilia brachybursa (Mawson, 1961), Odilia carinatae Smales, 2008, Odilia dividua Smales, 2014, Odilia emanuelae (Mawson, 1961), Odilia implexa Smales, 2008, Odilia mallomyos Hasegawa \& Syafruddin, 1994, Odilia mamasaensis Hasegawa, Miyata \& Syafruddin, 1999, Odilia mawsonae (Durette-Desset, 1969), Odilia maxomyos Hasegawa, Miyata \& Syafruddin, 1999, Odilia melomyos (Mawson, 1961), Odilia moatensis Hasegawa, Miyata \& Syafruddin, 1999, Odilia polyrhabdote (Mawson, 1961), Odilia praeputialis Gibbons \& Spratt, 1995, Odilia similis Smales, 2009, Odilia tasmaniensis Gibbons \& Spratt, 1995, Odilia sulawesiensis Hasegawa, Miyata \& Syafruddin, 1999, and Odilia wauensis Smales, 2010. The species Odilia uromyos (Mawson, 1961) as well as Odilia sp. 1 and Odilia sp. 2 of Hasegawa \& Syafruddin [14], whose synlophes were not illustrated, were not included in the study.

The methods used for the study and description of the synlophe follow the terms and criteria provided by Durette-Desset [8] and Durette-Desset \& Digiani [9]. To indicate more accurately the position of the ridges around the body circumference, the body section may be divided primarily into hemispheres or sides: right side and left side determined by the sagittal axis (SA) (Fig. 1A), and dorsal side and ventral side determined by the frontal axis (passing through the lateral hypodermal cords) (FA) (Fig. 1B). Applying the same principle, the ridges situated on the dorsal side are named dorsal ridges, those on the left side left ridges, etc. More complex synlophes usually require for their description a division of the section into quadrants or even into octants. The intersection of the SA and FA determines four quadrants referred as to leftdorsal, right-dorsal, right-ventral, and left-ventral (Fig. 1C). Similarly, the intersection of the diagonals of the quadrants defined above determines four other quadrants which may be referred to as mid-dorsal, mid-right, mid-ventral, and mid-left (Fig. 1D). The ridges situated in the different quadrants are named following the same principle as right-ventral ridges, left-dorsal ridges, etc. (Figs. 1C and 1D). A division into octants results in sections identified as dorsal-right-dorsal, right-right-dorsal, right-right-ventral, ventral-right-ventral, ventral-left-ventral, left-left-ventral, left-left-dorsal, and dorsal-left-dorsal, and the ridges on them are named consequently 


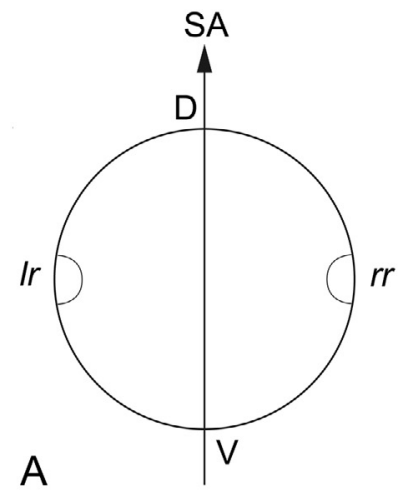

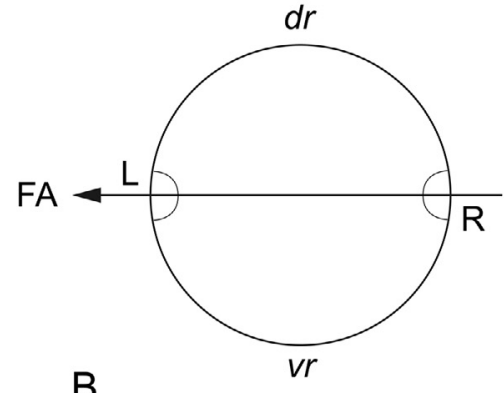

B

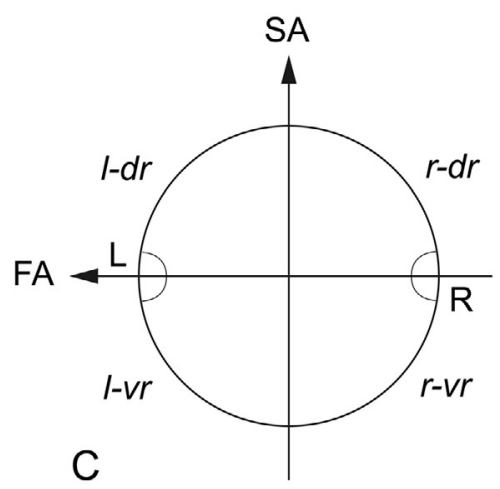

$\mathrm{D}$
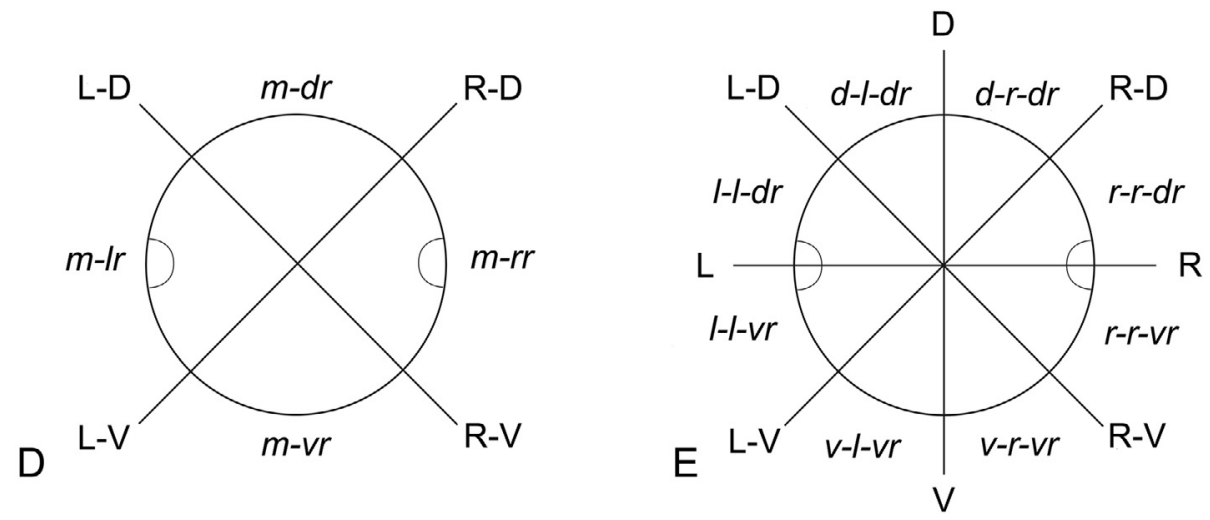

Figure 1. (A-E) Distribution of ridges around the body circumference. (A) According to the sagittal axis, ridges are named left ridges and right ridges. (B) According to the frontal axis, ridges are named dorsal ridges and ventral ridges. (C) Division into quadrants resulting from the intersection of sagittal and frontal axes. Ridges are named left-dorsal, right-dorsal, right-ventral, and left-ventral ridges. (D) Division into quadrants resulting from the intersection of the axes "right-ventral/left-dorsal" and "left-ventral/right-dorsal". Ridges are named mid-dorsal, mid-right, mid-ventral, and mid-left ridges. (E) Division into octants. Ridges are named dorsal-right-dorsal, right-right-dorsal, right-rightventral, ventral-right-ventral, ventral-left-ventral, left-left-ventral, left-left-dorsal, and dorsal-left-dorsal ridges. Abbreviations: D: dorsal side; FA: frontal axis; L: left side; LV/RD: left-ventral/right-dorsal axis; R: right side; RV/LD: right-ventral/left-dorsal axis; SA: sagittal axis; V: ventral side; dr: dorsal ridges; d-1-dr: dorsal-left-dorsal ridges; d-r-dr: dorsal-right-dorsal ridges; lr: left ridges; 1-dr: left-dorsal ridges; 1-vr: left-ventral ridges; 1-1-dr: left-left-dorsal ridges; 1-1-vr: left-left-ventral ridges; m-dr: mid-dorsal ridges; m-lr: mid-left ridges, m-rr: mid-right ridges, m-vr: mid-ventral ridges; r-dr: right-dorsal ridges; rr: right ridges; r-vr: right-ventral ridges; r-r-dr: right-right-dorsal ridges; r-r-vr: right-right-ventral ridges; vr: ventral ridges, v-l-vr: ventral-left-ventral ridges; v-r-vr: ventral-right-ventral ridges.

as dorsal-right-dorsal ridges, right-right-dorsal ridges, etc. (Fig. 1E).

As proposed in a previous article [4], the terms "right ridge" and "left ridge" when used in the singular, indicate the single ridge closest to the right and left lateral fields, respectively.

In the Heligmosomoidea, the ridges are usually numbered according to an axis of orientation which separates them into two groups with tips pointing in opposing directions. The axis of orientation is always directed from the right-ventral quadrant to the left-dorsal quadrant and in the Nippostrongylinae, its inclination ranges from $1^{\circ}$ to $90^{\circ}$ on the sagittal axis, depending on the species. At $90^{\circ}$, it overlaps the frontal axis passing through the lateral cords. The numbering of the ridges always begins on the left side and by definition, ridge 1 is situated dorsally to the axis and ridge 1' is situated ventrally. If the axis is frontal, it separates one group of dorsal ridges numbered 1 to $n$ and another of ventral ridges numbered 1' to $n$ '. If the axis is oblique, it separates one group of right-dorsal ridges numbered 1 to $n$ and another of left-ventral ridges numbered 1' to $n^{\prime}$ (Fig. 2A).

The left ridge may be homologous with ridge 1' (Fig. 2A) or distinct from it (Figs. 2B-G). This seems to be a strong character which allowed the rearrangement of several species in the revision of genera such as in Neoheligmonella Durette-Desset, 1971 [3] and Paraheligmonelloides Fukumoto, Kamiya \& Suzuki, 1980 [4].

The main synlophe characters used to separate the different genera were the following: (1) presence or absence of a careen; (2) size of ridges forming the careen; (3) position and development of ridge 1'; (4) development of the left ridge; (5) development of the right ridge; (6) size of the ridges; (7) distribution of the largest ridges; (8) presence of cuticular dilatations; and (9) discontinuity of ridges.

The description of the bursa follows Durette-Desset \& Digiani [10]. Other characters, especially of the bursa and 


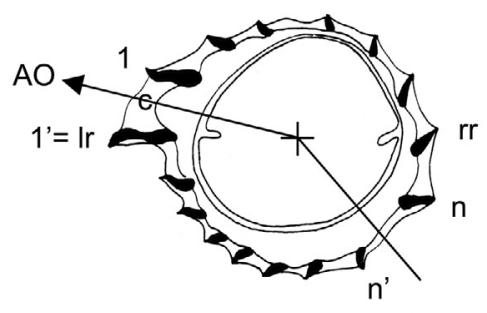

A

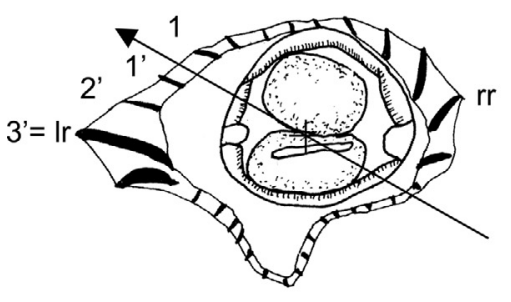

C

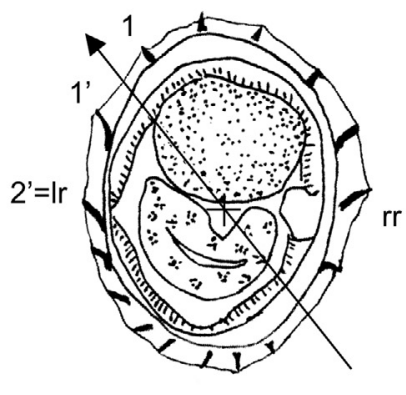

F

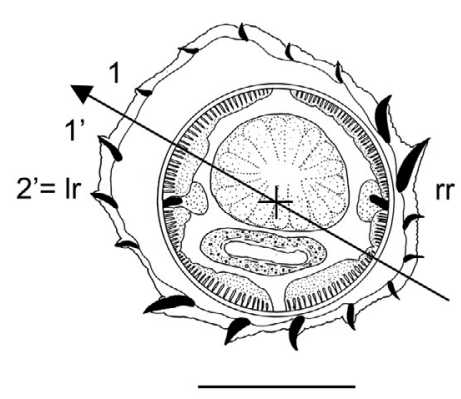

D

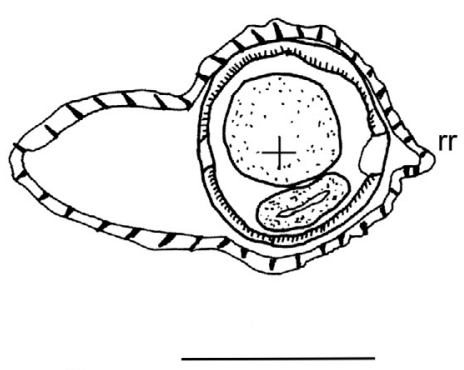

G

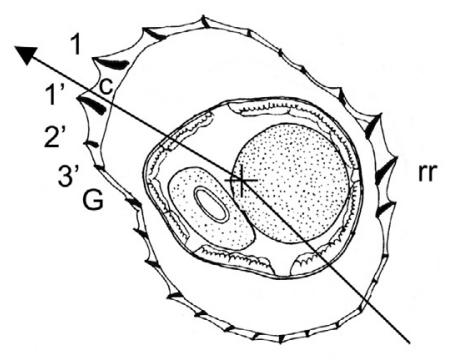

B

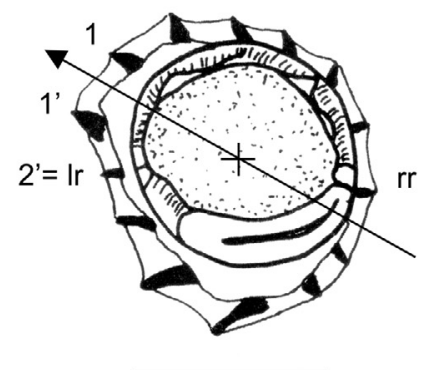

E

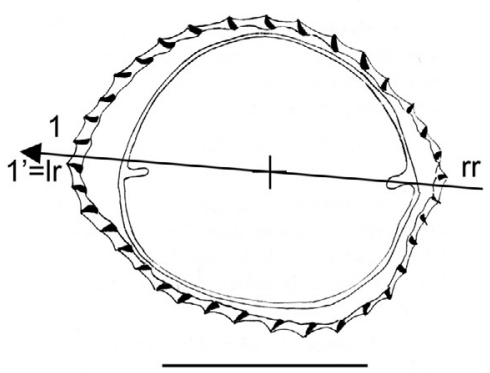

$\mathrm{H}$

Figure 2. Synlophes at mid-body of the genera treated in this work. Type-species. (A) Odilia (O. mackerrasae), male. (B) Hasegawanema $\mathrm{n}$. gen. (Hasegawanema mamasaense n. comb), female. C, Hughjonestrongylus (H. ennisae), female. (D) Chisholmia n. gen. (Chisholmia bainae n. comb.), male. (E) Lesleyella n. gen. (Lesleyella wauensis n. comb.), female. (F) Sanduanensis n. gen. (Sanduanensis dividua $\mathrm{n}$. comb.), female. (G) Parasabanema (P. szalayi), male. (H) Equilophos n. gen. (Equilophos polyrhabdote n. comb.), female. Abbreviations: 1, 1', 2', 3': ridges 1, 1', 2', 3'; AO: axis of orientation of the ridges; c: careen; G: gap; lr: left ridge; n: last dorsal ridge; n': last ventral ridge; rr: right ridge. A, H, modified from [5]. B, modified from [16]. C, G, modified from [26]. D, modified from [1]. E, modified from [20]. F, modified from [25]. Scale-bars: $50 \mathrm{~mm}$.

spicules are included in the generic definitions. The abbreviation $\mathrm{SpL} / \mathrm{BL}$ refers to the spicule length as a proportion of the body length, expressed as a percentage. The nomenclature of the hosts and their taxonomy at the suprageneric level follow Musser \& Carleton [18].

\section{Results}

\section{Characters of the Synlophe}

1. Presence or absence of a careen and

2. Relative size of ridges forming the careen
- The species O. brachybursa, O. emanuelae, O. mackerrasae, $O$. melomyos, and $O$. tasmaniensis possess a careen made up of two well-developed ridges, larger than the others. The ventral ridge of the careen is slightly larger than the dorsal one in O. brachybursa, O. mackerrasae, and O. tasmaniensis; markedly larger in $O$. emanuelae and $O$. melomyos.

- The species $O$. mallomyos, O. mamasaensis, O. maxomyos, O. moatensis, and $O$. sulawesiensis possess a careen made up of two thin ridges, comparable in size to the right ridge and the ridges adjacent to it. Both ridges of the careen have the same size in $O$. mamasaensis, O. moatensis, and $O$. sulawesiensis; the ventral ridge is slightly larger in $O$. mallomyos and $O$. maxomyos. 
- The careen is absent in O. bainae, O. carinatae, O. dividua, O. implexa, O. mawsonae, O. polyrhabdote, $O$. praeputialis, $O$. similis, and $O$. wauensis.

3. Position and development of ridge 1'

(a) Ridge 1' is the left ridge, situated in the left lateral field.

- It is the largest ridge in O. brachybursa, O. emanuelae, $O$. mackerrasae, $O$. melomyos, and $O$. tasmaniensis.

- It is as developed as the other ridges in O. mawsonae, $O$. polyrhabdote, and $O$. similis.

(b) Ridge 1' is not the left ridge and is situated in the dorsal left quadrant.

- Ridge 1' is among the largest ridges in $O$. carinatae, O. dividua, O. mallomyos, O. mamasaensis, O. maxomyos, $O$. moatensis, $O$. sulawesiensis, and $O$. wauensis.

- Ridge $1^{\prime}$ is among the smallest ridges in $O$. bainae, $O$. mawsonae, and O. implexa.

- Ridge 1' is as developed as the other left ridges in O. praeputialis.

4. Development of the left ridge

- The left ridge is the largest ridge in O. brachybursa, $O$. emanuelae, O. mackerrasae, O. melomyos, and $O$. tasmaniensis (where it is homologous with ridge 1 ').

- It is among the largest ridges in O. dividua and $O$ implexa.

- It is among the smallest ridges in O. bainae, O. carinatae, $O$. mawsonae, and $O$. wauensis.

- It is small and similar in size to all the other ridges in $O$. polyrhabdote and $O$. similis.

- It is as small as the other left ridges in O. praeputialis.

- It is replaced by a gap in $O$. mallomyos, O. mamasaensis, $O$. maxomyos, $O$. moatensis, and $O$. sulawesiensis.

5. Development of the right ridge

- The right ridge is well developed and larger than the adjacent ridges in $O$. bainae, $O$. brachybursa, $O$. carinatae, $O$. emanuelae, O. mackerrasae, O. mallomyos, O. mamasaensis, O. mawsonae, O. maxomyos, O. melomyos, O. moatensis, $O$. tasmaniensis, and $O$. sulawesiensis.

- It is well developed and of comparable size to the adjacent ridges in $O$. implexa.

- It is moderately developed and of the same size as the adjacent ridges in $O$. carinatae, $O$. dividua and O. mackerrasae.

- It is poorly developed and smaller than the right-dorsal ridges but larger than the right-ventral ridges in $O$. praeputialis and $O$. wauensis.

- It is poorly developed and of similar size to the remaining ridges in $O$. polyrhabdote and $O$. similis.
6. Size of the ridges

- All ridges are small and of similar size in O. polyrhabdote, $O$. similis, and $O$. praeputialis.

- Ridges are unequal in size, but not markedly. Medium-sized to small ridges in $O$. bainae, O. brachybursa, O. carinatae, O. dividua, O. emanuelae, O. mallomyos, O. mackerrasae, $O$. mawsonae, $O$. melomyos, $O$. tasmaniensis and $O$. wauensis. Small to minute ridges in $O$. mamasaensis, $O$. maxomyos, $O$. moatensis, and $O$. sulawesiensis.

- Ridges are markedly unequal in size (few hypertrophied ridges and remaining ridges small) in $O$. implexa.

No clear gradients in ridge size were observed in the species studied. In certain species, such as $O$. mackerrasae, O. tasmaniensis, $O$. maxomyos, and $O$. implexa, diminishing gradients in size were observed but frequently in only one of both sexes and it is apparently not a stable character.

\section{Position of the largest ridges}

- In O. mackerrasae, O. mallomyos, O. mamasaensis, O. maxomyos, O. moatensis (female), and O. sulawesiensis the largest ridges are the careen and the ridges associated with the right ridge (right ridge plus 1-2 ridges situated dorsally to it).

- In O. brachybursa, O. emanuelae, O. melomyos, and $O$. tasmaniensis the largest ridges are the careen, the ridges associated with the right ridge, and the ventral-leftventral ridges.

- In O. wauensis the largest ridges are ridge 1', and the ventral-left-ventral ridges.

- In O. implexa, O. carinatae females, and O. dividua the largest ridges are the mid-left and mid-right ridges.

- In the male of $O$. carinatae the largest ridges are the careen and the mid-right ridges.

- In $O$. bainae the largest ridges are the ridges associated with the right ridge and the ventral-left-ventral ridges.

- In the male of $O$. mawsonae, at mid-body, the largest ridges are the ridges associated with the right ridge. In the anterior part of the body, the largest ridges are also the mid-left and left-ventral ridges.

- In O. polyrhabdote and $O$. similis no ridges are markedly larger than the others.

- In O. praeputialis the largest ridges are the mid-left ridges, and dorsal, right-dorsal ones.

\section{Presence of cuticular dilatations}

- Two cuticular dilatations (or at least one), situated in the left-dorsal and right-ventral quadrants, are present in O. brachybursa, O. carinatae, O. emanuelae, O. implexa, O. mackerrasae, O. mallomyos, O. mamasaensis, O. mawsonae, O. maxyomyos, $O$. melomyos, O. moatensis, O. praeputialis, O. sulawesiensis, and O. tasmaniensis. 
- The cuticular dilatations are absent in O. bainae, O. dividua, O. mawsonae, O. polyrhabdote, O. similis, and $O$. wauensis.

\section{Discontinuity of ridges}

- In O. mackerrasae and O. dividua the ridges are discontinuous on the ventral side of the body. They are continuous in the other species.

\section{Discussion}

Since some of the characters analyzed were frequently associated with one another, we were able to group the species treated into eight groups:

\section{Groups (1 and 2), species with a careen}

1. Species with a careen of medium size and right ridge moderately developed. The left ridge is ridge 1'. The largest ridges are the careen, the ridges associated with the right ridge and the left-ventral ridges (though in $O$. mackerrasae the left-ventral ridges are small). Presence of double cuticular dilatation. Five species of Odilia: O. mackerrasae (type species of the genus), O. brachybursa, O. emanuelae, $O$. melomyos, and O. tasmaniensis (Fig. 2A).

2. Species with a careen of small size and right ridge comparable in size to careen. Ridges adjacent to careen very small. Left ridge distinct from ridge 1', poorly developed or replaced by a gap. Though small, the careen and the right ridge are the largest ridges. Presence of double cuticular dilatation. Five species: O. mallomyos, O. mamasaensis, $O$. maxomyos, $O$. moatensis (female), and $O$. sulawesiensis (Fig. 2B, 3B-E).

\section{Groups (3-8), species without a careen}

3. Species with ridges markedly unequal in size. Left ridge distinct from ridge 1'. Mid-left and mid-right ridges largest. Presence of double cuticular dilatation. One species: O. implexa (Fig. 3F).

4. Species with ridges slightly unequal in size. Left ridge distinct from ridge 1 '. The largest ridges are those associated with the right ridge and the left-ventral ridges. Cuticular dilatations absent. Two species: $O$. bainae (Fig. 2D) and O. mawsonae (Fig. 3A).

5. Species with ridges unequal in size. Left ridge distinct from ridge 1'. Left ridge medium-sized, right ridge small. Largest ridges: ridge 1', right-right-dorsal ridges (except the right ridge) and ventral-left-ventral ridges. Cuticular dilatations absent. One species: O. wauensis (Fig. 2E).
6. Species with ridges slightly unequal in size. Left ridge distinct from ridge 1'. Left ridge and right ridge of similar size. Mid-left ridges and mid-right ridges largest. Cuticular dilatations absent. One species: $O$. dividua (Fig. 2F).

7. Species with small ridges slightly unequal in size. Left ridges largest. Presence of double cuticular dilatation. One species: O. praeputialis (Fig. 3G).

8. Species with small ridges subequal in size. Mid-right ridges minute. Cuticular dilatations absent. Two species: O. polyrhabdote (Fig. $2 \mathrm{H}$ ) and $O$. similis (Fig. $3 \mathrm{H}$ ).

\section{New classification proposed}

Based on the groups of species mentioned above, we propose to group the species of the present-day genus Odilia into eight genera of which five are new. Seven out of the 18 species studied are attributed to the existing genera Odilia sensu stricto Durette-Desset, 1973 (5 species), Hughjonestrongylus Digiani \& Durette-Desset, 2014 (1 species), and Parasabanema Smales $\&$ Heinrich, 2010 (1 species). The other species were distributed in the following new genera: Hasegawanema n. gen. (5 species), Chisholmia n. gen. (2 species), Lesleyella n. gen. (1 species), Sanduanensis n. gen. (1 species), and Equilophos n. gen. (2 species).

\section{I- Genus Odilia Durette-Desset, 1973 (Fig. 2A)}

Type species: Odilia mackerrasae (Mawson, 1961).

Hosts: Muridae (Rodentia).

Host site: Small intestine.

Distribution: Mainland Australia, Tasmania.

Definition: Heligmonellidae, Nippostrongylinae. Synlophe with 14-18 ridges in both sexes. Ridges continuous (except type species with ventral ridges discontinuous). Careen supported by two medium-sized ridges, at least in proximal part of body, with ventral ridge longer. Ridge 1' is the left ridge. Ridges unequal in size, median to small. Careen, ridges associated with the right ridge, and ventral-left-ventral ridges, largest. Other ridges (mid-dorsal, right-ventral) smaller. Presence of two minute ridges or a gap dorsally adjacent to largest left-ventral ridges (except type species). Cuticular dilatations situated on left-dorsal and right-ventral quadrants. Axis (es) of orientation oblique. Characteristic bursal pattern of types 2-2-1, 1-3-1. Dorsal ray divided within proximal half. Each spicule ending in one tip. SpL/BL: $7-16 \%$.

Other species: O. brachybursa (Mawson, 1961), O. emanuelae (Mawson, 1961), O. melomyos (Mawson, 1961), O. tasmaniensis Gibbons \& Spratt, 1995.

\section{II- Genus Hasegawanema n. gen. (Figs. 2B and $3 \mathrm{~B}-\mathrm{E})$}

urn:1sid:zoobank.org:act:A3C86F23-57EA-4BE5-889E377490B752CB 


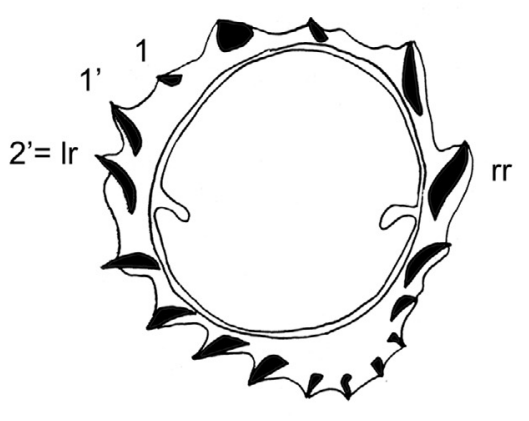

A

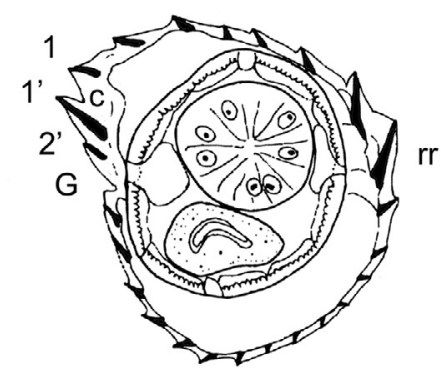

C

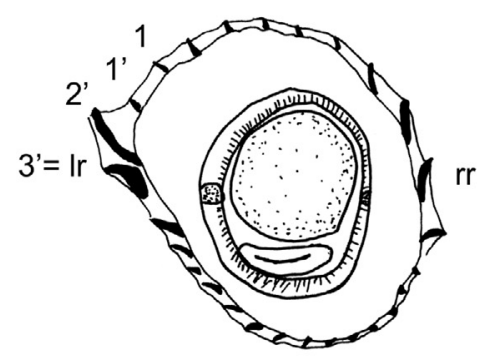

F

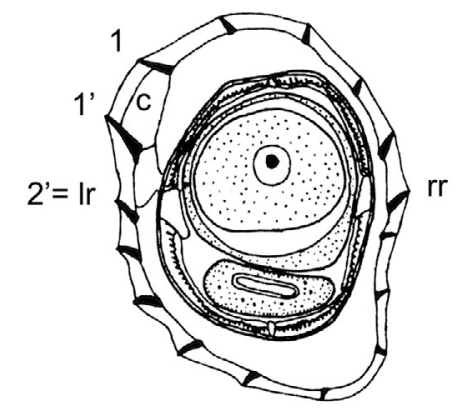

$\mathrm{D}$

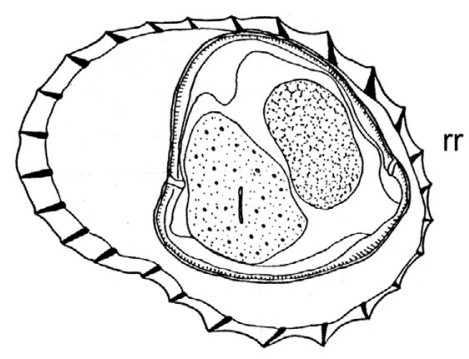

G

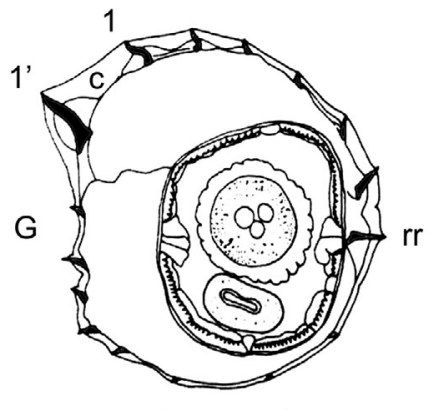

B

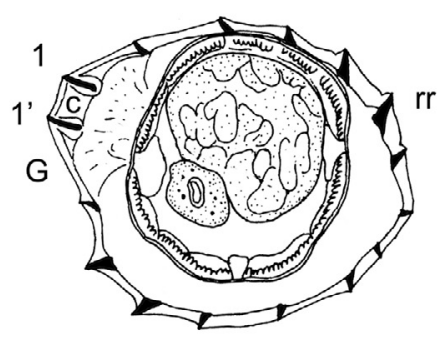

E

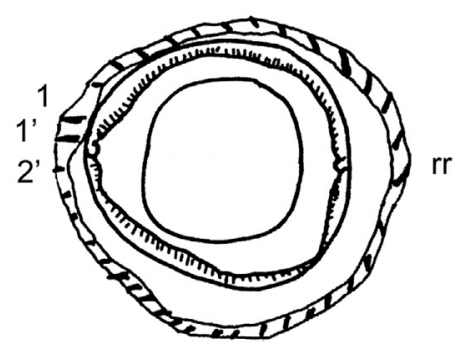

$\mathrm{H}$

Figure 3. Synlophes of the genera treated in this work. Other species. (A) within anterior part of body, Chisholmia mawsonae n. comb., male. (B-H) at mid-body: (B) Hasegawanema mallomyos n. comb., female. (C) Hasegawanema maxomyos n. comb., male. (D) Hasegawanema moatense n. comb., female. (E) Hasegawanema sulawesiense n. comb., female. (F) Hughjonestrongylus implexus n. comb., female. (G) Parasabanema praeputiale n. comb., female. (H) Equilophos similis n. comb., male. Abbreviations: 1, 1', 2', 3': ridges 1, 1', 2', 3'; c: careen; G: gap; lr: left ridge; rr: right ridge. A, modified from [5]. B, modified from [12]. C-E, modified from [16]. F, modified from [21]. G, modified from [11]. H, modified from [22]. Scale-bars: $50 \mathrm{~mm}$.

Type species: Hasegawanema mamasaense (Hasegawa, Miyata \& Syafruddin, 1999) n. comb.

Hosts: Muridae (Rodentia).

Host site: Small intestine.

Distribution: Indonesia.

Etymology: The genus is named in honor of Pr. Hideo Hasegawa (Faculty of Medicine, Oita University, Japan), in recognition of his valuable contribution to knowledge on the Oriental Nippostrongylinae.

Definition: Heligmonellidae, Nippostrongylinae. Synlophe with 15-26 ridges in both sexes. Ridges continuous. Careen supported by two small ridges with ventral one generally slightly larger. Ridge 1' distinct from left ridge. Ridges unequal in size, small to minute. Careen and ridges associated with right ridge, largest. Other ridges very small or minute. Left ridge minute or replaced by a gap in front of the left lateral field. Axis (es) of orientation oblique. Characteristic bursal pattern of type 2-2-1. Dorsal ray divided within proximal half. Each spicule ending in one tip. SpL/BL: 6-25\%.

Other species: Hasegawanema mallomyos (Hasegawa \& Syafruddin, 1994) n. comb., Hasegawanema maxomyos (Hasegawa, Miyata \& Syafruddin, 1999) n. comb., Hasegawanema 
moatense (Hasegawa, Miyata \& Syafruddin, 1999) n. comb., Hasegawanema sulawesiense (Hasegawa, Miyata \& Syafruddin, 1999) n. comb.

\section{III- Genus Hughjonestrongylus Digiani \& Durette- Desset, 2014 (Figs. 2C and 3F)}

Type species: Hughjonestrongylus ennisae (Smales \& Heinrich, 2010) Digiani \& Durette-Desset, 2014.

Hosts: Muridae (Murinae).

Host site: Small intestine.

Distribution: Papua New Guinea, Papua Indonesia.

Definition: Heligmonellidae, Nippostrongylinae. Synlophe with $20-30$ ridges in both sexes. Ridges continuous. Careen absent. Ridges markedly unequal in size. Left ridge distinct from ridge 1'. Mid-left and mid-right ridges largest. Left ridges generally larger than right ones. Presence of left-dorsal and right-ventral cuticular dilatations. Axis(es) of orientation oblique. Characteristic bursal pattern of types 1-4 and 2-3. Dorsal ray divided within distal half. Spicules thick, each one ending in one or three tips. SpL/BL 10-15\%.

Other species: Hughjonestrongylus amplicaudae (Smales \& Heinrich, 2010) Digiani \& Durette-Desset, 2014, Hughjonestrongylus implexus (Smales, 2008) n. comb., Hughjonestrongylus mirzai (Smales, 2009) Digiani \& Durette-Desset, 2014, Hughjonestrongylus singauwaensis (Smales \& Heinrich, 2010) Digiani \& Durette-Desset, 2014, Hughjonestrongylus. sp. of Smales [24].

\section{IV- Genus Chisholmia n. gen. (Figs. 2D and 3A)}

urn:lsid:zoobank.org:act:680A783E-5BB1-473A-836F4E6DB762F649

Type species: Chisholmia bainae (Beveridge \& DuretteDesset, 1992) n. comb.

Hosts: Muridae (Murinae).

Host site: Small intestine.

Distribution: Mainland Australia, Tasmania.

Etymology: The genus is named in honor of Dr. Leslie Chisholm, recognized researcher on marine parasites at the University of Adelaide (Australia), and Manager of the Parasitology and Arachnology Collections at the South Australian Museum.

Definition: Heligmonellidae, Nippostrongylinae. Synlophe with 16-22 ridges in both sexes. Ridges continuous. Careen absent. At least in proximal part of body, ridges slightly unequal in size, median to small. Left ridge distinct from ridge 1 '. Left ridge smaller than right ridge. Ridges associated with right ridge and ventral-left ridges largest. Axis (es) of orientation oblique. Absence of cuticular dilatations. Characteristic bursal pattern of types 2-2-1 and 1-4. Dorsal ray divided within proximal half. Each spicule ending in one tip. SpL/ BL: $7-13 \%$.

Other species: Chisholmia mawsonae (Durette-Desset, 1969) n. comb.

\section{V- Genus Lesleyella n. gen. (Fig. 2E)}

urn:Isid:zoobank.org:act:241C45B2-8EE9-419E-B14B7A85990D2C3D

Type and sole species: Lesleyella wauensis (Smales, 2010) n. comb.

Hosts: Muridae (Rodentia).

Host site: Small intestine.

Distribution: Papua New Guinea.

Etymology: The genus is named in honor of Dr Lesley R. Smales in recognition of her significant contribution to knowledge on the Australasian helminths.

Definition: Heligmonellidae, Nippostrongylinae. Synlophe with 14-17 ridges in both sexes. Ridges continuous. Careen absent. Ridges unequal in size, median to small. Left ridge distinct from ridge 1'. Ridge 1', right-dorsal ridges (except right ridge) and ventral-left-ventral ridges largest. Axis of orientation oblique. Characteristic bursal pattern of type 1-4 with short common trunk. Dorsal ray divided within proximal half. Each spicule ending in one tip. SpL/BL: $7 \%$.

\section{VI- Genus Sanduanensis n. gen. (Fig. 2F)}

urn:1sid:zoobank.org:act:0CAA299C-8055-4D0D-8423B6F482E02B02

Type and sole species: Sanduanensis dividua (Smales, 2014) n. comb.

Hosts: Muridae (Rodentia).

Host site: Small intestine.

Distribution: Papua New Guinea.

Etymology: The genus is named after one of the localities where the species was found.

Definition: Heligmonellidae, Nippostrongylinae. Synlophe with 16 ridges in both sexes. Dorsal ridges continuous, ventral ridges discontinuous. Careen absent. Ridges unequal in size, median to small. Left ridge distinct from ridge 1'. Mid-left and mid-right ridges largest. Absence of cuticular dilatations. Characteristic bursal pattern of type 1-4. Dorsal ray divided within proximal half. Each spicule ending in one tip. SpL/ BL: $13.2 \%$.

\section{VII- Genus Parasabanema Smales \& Heinrich, 2010 (Figs. 2G and 3G)} 2010.

Type species: Parasabanema szalayi Smales \& Heinrich,

Hosts: Muridae (Rodentia).

Host site: Small intestine.

Distribution: New Guinea, Australia.

Definition: Heligmonellidae, Nippostrongylinae. Synlophe with $22-45$ ridges in both sexes. Ridges continuous. Careen absent. Small ridges slightly unequal in size. Mid-left, rightright-dorsal and mid-ventral ridges largest. Right-right-ventral ridges minute. Presence of left-dorsal and right-ventral cuticular dilatations. Axis of orientation oblique. Characteristic bursal pattern of type 1-4. Dorsal ray divided within distal half. Each spicule ending in one tip. SpL/BL: 8\%. 
Other species: Parasabanema praeputiale (Gibbons \& Spratt, 1995) n. comb.

\section{VIII- Genus Equilophos n. gen. (Figs. 2H and $3 \mathrm{H}$ )}

urn:1sid:zoobank.org:act:2B27AD22-D6F8-4CFF-8C68B9682F6E92FF comb.

Type species: Equilophos polyrhabdote (Mawson, 1961) n.

Hosts: Muridae (Rodentia).

Host site: Small intestine.

Distribution: Australia.

Etymology: The genus was named in this way because the ridges are of similar size.

Definition: Heligmonellidae, Nippostrongylinae. Synlophe with 35-36 ridges in both sexes. Ridges continuous. Careen absent. Ridges small, of similar size, except mid-right ridges, minute. Axis of orientation almost subfrontal. Characteristic bursal pattern of type 1-4. Each spicule ending in one tip. SpL/BL: $10-11 \%$.

Other species: Equilophos similis (Smales, 2009) n. comb.

\section{Comments}

Odilia uromyos is the most prevalent species present in Uromys spp. from Australia and Papua New Guinea [17, 27]. However, its synlophe has never been described in transverse section of the body. It was described as having up to 40 small, apparently subequal ridges in the distal part of the male and 48 in the female [17]. This number of subequal ridges may correspond either to the genus Parasabanema or to Equilophos n. gen. However, other characters such as the bursal pattern, which is apparently 2-3 [17] and the ratio SpL/BL of $16 \%$ do not correspond with any of these two genera. Based on the available data, $O$. uromyos cannot be placed in the generic arrangement proposed above, although the species is validated by a number of characters including the number of ridges, bursal pattern, and spicule shape. It is temporarily considered as a Nippostrongylinae incertae sedis.

Odilia carinatae, also parasitic in Uromys spp., was described from Papua New Guinea [21]. The synlophe was described and illustrated in males and females but the orientation of the ridges is not completely clear and its interpretation is difficult. In both sexes, a careen is absent, the ridges are unequal in size, the mid-right ridges are among the largest ridges, and there is a left or left-dorsal cuticular dilatation. However, in the male the cuticular dilatation is more marked and the largest ridges on the left side are the left-dorsal ridges, apparently two dorsal and two ventral to the axis of orientation, whereas in the female, the largest left ridges are the mid-left ridges, apparently all ventral to the axis of orientation. The synlophe characters of the female evoke those of the genus Hughjonestrongylus, with several species reported from Melomys spp., Paramelomys, and Chiruromys but also Uromys spp., all from Papua New Guinea [4, 22, 24, 26, this work]. The synlophe characters in both sexes, as well as the spicular characters of the male [21], enable us to distinguish these specimens from all the other species treated herein: however, they cannot be placed in the generic arrangement proposed above. Therefore, it would be preferable to consider these specimens as Nippostrongylinae incertae sedis, while awaiting improved descriptions of the synlophe in both sexes.

Two other species were reported as Odilia sp. 1 and Odilia sp. 2, parasitic in Rattus cf. morotaiensis from the Molucca Islands, Indonesia [14]. The synlophes of both species were described but not illustrated, and the data provided are insufficient to assign the species to any of the genera proposed here.

Table 1 provides a list of the species included in the former genus Odilia, with their new systematic position as proposed herein.

Table 2 provides the list of genera of the "Odilia" complex, along with the species list, host spectrum, and biogeographical distribution.

At this point, it is interesting to note that all native rodents of Australia and New Guinea (Sahul region) belong to the $\mathrm{Mu}-$ rinae [18]. Among them, two groups are recognized. The first and most speciose is a taxonomically diverse but phylogenetically connected group of old endemics [19]. Recent studies support the monophyly of the old endemics, the result of a single colonization event 5.1-5.5 million years ago and subsequent rapid diversification within the region [19]. This was followed by multiple dispersal events between Australia and New Guinea, related to sea level fluctuations [19].

The other group, called the new endemics, is composed of native species of Rattus, which are thought to be recent colonists (from about 1 million years ago) with a history independent from that of the remaining Sahulian murines [19].

The new generic arrangement proposed for the nippostrongylines belonging to the "Odilia complex" seems to follow a distribution which is apparently more related to different geographic areas than to definite host groups (see Table 2).

Species of Hughjonestrongylus, Sanduanensis, and Lesleyella are distributed among several genera of hosts belonging to different groups of the old endemics, but are all restricted to New Guinea.

Species of Parasabanema have a Sahulian distribution, being present in Australia and New Guinea and parasitizing members of different groups of the old endemics. Species of Equilophos also have a Sahulian distribution, with one species in an old endemic of New Guinea and another in a native Rattus of Australia.

Species of Odilia and Chisholmia are found in mainland Australia (one species in Tasmania), parasitizing members of different groups of old endemics but also species of native Rattus (new endemics).

All these taxa of Sahulian distribution are likely to have undergone high diversification accompanying that of their hosts, diversification which followed the first colonization of Sahul by the ancestors of the old endemics. The presence of certain genera (Equilophos, Parasabanema) in both Australia and New Guinea may also reflect the latter hosts' multiple dispersal events between these two areas. None of these genera with exclusively Sahulian distribution has species parasitic only in the new endemics. This may reinforce the hypothesis that they diversified mainly in the old endemics, whereas the presence of about four species in native species of Rattus could 
Table 1. List of species belonging to the former genus Odilia and their present systematic position.

\begin{tabular}{|c|c|}
\hline Species and Reference(s) & Systematic position after this work \\
\hline Odilia bainae Beveridge \& Durette-Desset, 1992 [1] & Chisholmia bainae n. comb. \\
\hline Odilia brachybursa (Mawson, 1961) [5-7, 17] & Odilia brachybursa \\
\hline Odilia carinatae Smales, 2008 [21] & Nippostrongylinae incertae sedis \\
\hline Odilia dividua Smales, 2014 [25] & Sanduanensis dividua $\mathrm{n}$. comb. \\
\hline Odilia emanuelae (Mawson, 1961) $[5-7,17,20]$ & Odilia emanuelae \\
\hline Odilia implexa Smales, 2008 [21] & Hughjonestrongylus implexus $\mathrm{n}$. comb. \\
\hline Odilia mackerrasae (Mawson, 1961) $[5-7,17]$ & Odilia mackerrasae \\
\hline Odilia mallomyos Hasegawa \& Syafruddin, 1994 [12] & Hasegawanema mallomyos n. comb. \\
\hline Odilia mamasaensis Hasegawa et al., 1999 [16] & Hasegawanema mamasaense $\mathrm{n}$. comb. \\
\hline Odilia mawsonae (Durette-Desset, 1969) [5-7] & Chisholmia mawsonae n. comb. \\
\hline Odilia maxomyos Hasegawa et al., 1999 [16] & Hasegawanema maxomyos $\mathrm{n}$. comb. \\
\hline Odilia melomyos (Mawson, 1961) [5-7, 17] & Odilia melomyos \\
\hline Odilia moatensis Hasegawa et al., 1999 [16] & Hasegawanema moatense $\mathrm{n}$. comb. \\
\hline Odilia polyrhabdote (Mawson, 1961) $[5-7,17]$ & Equilophos polyrhabdote n. comb. \\
\hline Odilia praeputialis Gibbons \& Spratt, 1995 [11] & Parasabanema praeputiale $\mathrm{n}$. comb. \\
\hline Odilia similis Smales, 2009 [22] & Equilophos similis n. comb. \\
\hline Odilia tasmaniensis Gibbons \& Spratt, 1995 [11] & Odilia tasmaniensis \\
\hline Odilia uromyos (Mawson, 1961) $[5-7,17,27]$ & Nippostrongylinae incertae sedis \\
\hline Odilia sulawesiensis Hasegawa et al., 1999 [16] & Hasegawanema sulawesiense $\mathrm{n}$. comb. \\
\hline Odilia wauensis Smales, 2010 [23] & Lesleyella wauensis n. comb. \\
\hline
\end{tabular}

Table 2. List of genera of the "Odilia" complex with the species list, host spectrum, and biogeographical distribution for each genus.

\begin{tabular}{|c|c|c|c|}
\hline Genus & Species & Hosts & Region \\
\hline \multirow[t]{5}{*}{ Odilia Durette-Desset, 1973} & brachybursa & Melomys & Australia \\
\hline & emanuelae & Rattus & Australia \\
\hline & mackerrasae & Melomys, Uromys & Australia \\
\hline & melomyos & Melomys, Uromys & Australia \\
\hline & tasmaniensis & Rattus & Tasmania \\
\hline \multirow[t]{2}{*}{ Chisholmia n. gen. } & bainae & Rattus, Pseudomys, Mastacomys & Australia \\
\hline & mawsonae & Melomys & Australia \\
\hline \multirow[t]{2}{*}{ Equilophos n. gen. } & polyrhabdote & Rattus & Australia \\
\hline & similis & Melomys & New Guinea (PNG) \\
\hline \multirow[t]{5}{*}{ Hasegawanema $\mathrm{n}$. gen. } & mallomyos & Mallomys & New Guinea (West Papua, Indonesia) \\
\hline & mamasaense & Maxomys & Sulawesi (Indonesia) \\
\hline & maxomyos & Maxomys & Sulawesi (Indonesia) \\
\hline & moatense & Maxomys & Sulawesi (Indonesia) \\
\hline & sulawesiense & Rattus & Sulawesi (Indonesia) \\
\hline \multirow{5}{*}{$\begin{array}{l}\text { Hughjonestrongylus Digiani \& } \\
\text { Durette-Desset, } 2014\end{array}$} & amplicaudae* & Paramelomys & New Guinea (PI) \\
\hline & ennisae* & Paramelomys & New Guinea (PNG) \\
\hline & implexus & Uromys & New Guinea (PNG) \\
\hline & mirzai** & Melomys & New Guinea (PNG) \\
\hline & singauwaensis* & Melomys & New Guinea (PNG, PI) \\
\hline Lesleyella $\mathrm{n}$. gen. & wauensis & Lorentzimys & New Guinea (PNG) \\
\hline Sanduanensis n. gen. & dividua & Pogonomys & New Guinea (PNG) \\
\hline Parasabanema Smales \& Heinrich, 2010 & $\begin{array}{l}\text { praeputiale } \\
\text { szalayi }\end{array}$ & $\begin{array}{l}\text { Zyzomys, Mesembriomys, Melomys } \\
\text { Paramelomys }\end{array}$ & $\begin{array}{l}\text { Australia } \\
\text { New Guinea (PNG, PI) }\end{array}$ \\
\hline
\end{tabular}

${ }_{* *}^{*}$ Described as a species of Paraheligmonelloides.

${ }^{* * *}$ Described as a species of Heligmonoides.

Abbreviations: PNG: Papua New Guinea; PI: Province of Papua, Indonesia. In bold print, type species. 
be attributed to events of host capture of the parasites from the first hosts in place.

On the other hand, the species grouped in Hasegawanema show a mainly extra Sahulian distribution (Table 2), with four out of five species found in endemic murines of Sulawesi [16], and only one species parasitic in West Papua (New Guinea) in one member of the old endemics [12]. Furthermore, species of Hasegawanema show certain synlophe characters, such as the left ridge being minute or replaced by a gap, which remind us strongly of species of Syafruddinema Digiani and DuretteDesset, 2014 [4], with two species parasitic in endemic murines of Sulawesi and a third in the Malay peninsula $[4,16]$. A similar close relationship with representatives of Sundaland (Southeast Asia and islands of the Sunda shelf) has also been found in other endemic heligmonellids of Sulawesi such as Hasanuddinia Hasegawa \& Syafruddin, 1994, with affinities with Rattustrongylus Ow-Yang et al., 1983 from peninsular Malaysia [13], or Maxomystrongylus Hasegawa \& Syafruddin, 1997 which has congeners in Kalimantan (Borneo) [15, 16]. Such a close relationship between the heligmonellids of Sulawesi and Sundaland is not unexpected since the endemic murid fauna of Sulawesi is most closely associated with that of the Asian mainland $[16,18]$.

\section{Key to the proposed genera}

1- Careen present (Figs. 2A, B). .2

1 '- Careen absent (Figs. 2C-H) ...3

2- Ridge 1' is left ridge (Fig. 2A).

Parasites of Melomys, Rattus, Uromys from mainland Australia and Tasmania..... Odilia Durette-Desset, 1973

2'- Ridge 1' distinct from left ridge. Left ridge minute or replaced by a gap (Fig. 2B).

Parasites of Mallomys, Maxomys, Rattus from Indonesia. Hasegawanema $\mathrm{n}$. gen.

3- Ridges subequal in size (Fig. 2H).

Parasites of Rattus, Uromys from Australia, Melomys from Papua New Guinea. Equilophos n. gen.

3'- Ridges unequal in size. .4

4- Left ridges oriented perpendicularly to body surface (Fig. 3G).

Parasites of Zyzomys, Mesembriomys, Melomys, Rattus, Uromys from Australia. Parasabanema Smales \& Heinrich, 2010

4'- Left ridges not oriented perpendicularly to body surface

5- Ventral-left-ventral ridges largest (Figs. 2D, E). . .6

5'- Lateral ridges largest (Fig. 2C)..................................

6- Right ridge larger than left ridge (Fig. 2D).

Parasites of Rattus, Pseudomys, Mastacomys, Melomys from mainland Australia and Tasmania ..Chisholmia n. gen.
6' Left ridge and right ridge of similar size (Fig. 2E). Parasites of Lorentzimys from Papua New Guinea Lesleyella $\mathrm{n}$. gen.

7- Ridges markedly unequal in size (Fig. 2C). All ridges continuous.

Parasites of Uromys from New Guinea .........................................Hughjonestrongylus n. gen.

7'- Ridges slightly unequal in size (Fig. 2F). Dorsal ridges continuous, ventral discontinuous.

Parasites of Pogonomys from New Guinea ...Sanduanensis n. gen.

Acknowledgements. The authors wish to thank M. Didier GeffardKuriyama (Muséum National d'Histoire Naturelle, Paris, France) for the drawings and edition of the figures, and Ms. Deborah Lynn Kay for the English revision. Thanks are extended to Dr David Spratt (CSIRO, Australia) and two anonymous reviewers for valuable comments and suggestions on earlier versions of the manuscript.

\section{References}

1. Beveridge I, Durette-Desset M-C. 1992. A new species of trichostrongyloid nematode, Odilia bainae, from a native rodent, Rattus fuscipes. Transactions of the Royal Society of South Australia, 116, 123-128.

2. Chandler AC. 1924. A new genus of trichostrongylid worms from the kangaroo. Parasitology, 16, 160-163.

3. Digiani MC, Durette-Desset M-C. 2013. Taxonomic revision of the genus Neoheligmonella Durette-Desset, 1971 (Nematoda, Heligmonellidae), parasitic mainly in African Muridae. Zoosystema, 35, 479-488.

4. Digiani MC, Durette-Desset M-C. 2014. Taxonomic revision of the Nippostrongylinae (Nematoda, Heligmonellidae) parasitic in Oriental Muridae. The genus Paraheligmonelloides Fukumoto, Kamiya \& Suzuki, 1980. Zootaxa, 3884, 81-88.

5. Durette-Desset M-C. 1969. Les systèmes d'arêtes cuticulaires chez les Nématodes Héligmosomes, parasites de Muridés australiens. Annales de Parasitologie Humaine et Comparée, 44, 733-747.

6. Durette-Desset M-C. 1971. Essai de classification des Nématodes Héligmosomes. Corrélation avec la paléobiogéographie des hôtes. Mémoires du Muséum national d'Histoire naturelle Nouvelle Série, Série A, Zoologie, 49, 1-126.

7. Durette-Desset M-C. 1973. Note rectificative sur le genre Austrostrongylus (Nématode). Annales de Parasitologie Humaine et Comparée, 48, 517-518.

8. Durette-Desset M-C. 1985. Trichostrongyloid nematodes and their vertebrate hosts: reconstruction of the phylogeny of a parasitic group. Advances in Parasitology, 24, 239-306.

9. Durette-Desset M-C, Digiani MC. 2005. The axis of orientation of the synlophe in the Heligmosomoidea (Nematoda, Trichostrongylina): a new approach. Parasite, 12, 195-202.

10. Durette-Desset M-C, Digiani MC. 2012. The caudal bursa in the Heligmonellidae (Nematoda: Trichostrongylina). Characterization and hypothesis on its evolution. Parasite, 19, 3-18.

11. Gibbons LM, Spratt DM. 1995. Two new species of Odilia (Nematoda: Heligmonellidae) from Australian rodents, with comments on O. bainae Beveridge \& Durette-Desset, 1992. Systematic Parasitology, 31, 67-79. 
12. Hasegawa H, Syafruddin. 1994. Odilia mallomyos sp. n. (Nematoda: Heligmonellidae) from Mallomys rothschildi weylandi (Rodentia: Muridae) of Irian Jaya, Indonesia. Journal of the Helminthological Society of Washington, 61, 208-241.

13. Hasegawa H, Syafruddin. 1994. Hasanuddinia maxomyos $\mathrm{n}$. gen., n. sp. Heligmonoides musseri n. sp. (Nematoda: Heligmonellidae) collected from endemic murines of Sulawesi, Indonesia. Journal of Parasitology, 80, 781-788.

14. Hasegawa H, Syafruddin. 1995. Nippostrongylus marhaeniae sp. n. and other nematodes collected from Rattus cf. morotaiensis in North Halmahera, Molucca Islands, Indonesia. Journal of the Helminthological Society of Washington, 62, 111-116.

15. Hasegawa H, Syafruddin. 1997. Maxomystrongylus yasumai gen. and sp. n. (Nematoda: Trichostrongylina: Heligmonellidae) collected from murine rodents in Kalimantan, Indonesia. Journal of the Helminthological Society of Washington, 64, 263-268.

16. Hasegawa H, Miyata A, Syafruddin. 1999. Six new nematodes of the Heligmonellidae (Trichostrongylina) collected from endemic murines of Sulawesi, Indonesia. Journal of Parasitology, 85, 513-524.

17. Mawson P. 1961. Trichostrongyles from rodents in Queensland, with comments on the genus Longistriata (Nematoda: Heligmosomatidae). Australian Journal of Zoology, 6, 791-826.

18. Musser GG, Carleton MD. 2005. Family Muridae, in Mammal Species of the World: a taxonomic and geographic reference. Wilson DE, Reeder DM, Editors. The Johns Hopkins University Press: Baltimore. p. 1189-1531.

19. Rowe KC, Reno ML, Richmond DM, Adkins RM, Steppan SJ. 2008. Pliocene colonization and adaptive radiations in Australia and New Guinea (Sahul): Multilocus systematics of the old endemic rodents (Muroidea: Murinae). Molecular Phylogenetics and Evolution, 47, 84-101.

20. Smales LR. 2005. A redescription of Odilia emanuelae (Nematoda: Trichostrongylina: Heligmonellidae) from Australian rodents with a key and comments on the genus Odilia. Transactions of the Royal Society of South Australia, 129, 59-64.

21. Smales LR. 2008. Three new species of Heligmonellidae (Nematoda: Trichostrongyloidea) from Melomys, Paramelomys, and Uromys (Rodentia: Muridae) from Papua Indonesia and Papua New Guinea. Comparative Parasitology, 75, 52-60.

22. Smales LR. 2009. Helminths of Melomys rufescens and Melomys spp. (Muridae: Hydromyinae) from Papua New Guinea with the descriptions of a new genus and five new species in the Heligmonellidae (Nematoda:Trichostrongyloidea). Raffles Bulletin of Zoology, 57, 5-15.

23. Smales LR. 2010. The gastrointestinal helminths of Lorentzimys nouhuysi (Rodentia: Muridae) with descriptions of two new genera and three new species (Nematoda) from Papua New Guinea. Journal of Parasitology, 96, 602-613.

24. Smales LR. 2011. The gastrointestinal helminths of Chiruromys vates (Rodentia: Muridae) with the description of a new species (Nematoda: Heligmonellidae) from Papua New Guinea. Comparative Parasitology, 78, 327-332.

25. Smales LR. 2014. Gastrointestinal helminths (Cestoda, Chabertiidae and Heligmonellidae) of Pogonomys loriae and Pogonomys macrourus (Rodentia: Muridae) from Papua Indonesia and Papua New Guinea with the description of a new genus and two new species. Zootaxa, 3889, 92-106.

26. Smales LR, Heinrich B. 2010. Gastrointestinal nematodes of Paramelomys rubex (Rodentia: Muridae) from Papua Indonesia and Papua New Guinea with the descriptions of three new genera and four new species of Heligmonellidae and Herpetostrongylidae (Nematoda: Trichostrongylina). Zootaxa, 2672, $1-28$.

27. Smales LR, Spratt DM. 2010. Helminth assemblages of Uromys spp. (Muridae: Hydromyinae) from Australia, Papua New Guinea and Papua Indonesia and comparison with assemblages in Melomys spp. Australian Journal of Zoology, $56,85-94$.

Cite this article as: Durette-Desset M-C \& Digiani MC: Taxonomic revision of the Nippostrongylinae (Nematoda, Heligmonellidae) parasites of Muridae from the Australasian region. The genus Odilia Durette-Desset, 1973. Parasite, 2015, $22,32$.

\section{O PARASTE}

Reviews, articles and short notes may be submitted. Fields include, but are not limited to: general, medical and veterinary parasitology; morphology, including ultrastructure; parasite systematics, including entomology, acarology, helminthology and protistology, and molecular analyses; molecular biology and biochemistry; immunology of parasitic diseases; host-parasite relationships; ecology and life history of parasites; epidemiology; therapeutics; new diagnostic tools.

All papers in Parasite are published in English. Manuscripts should have a broad interest and must not have been published or submitted elsewhere. No limit is imposed on the length of manuscripts.

Parasite (open-access) continues Parasite (print and online editions, 1994-2012) and Annales de Parasitologie Humaine et Comparée (1923-1993) and is the official journal of the Société Française de Parasitologie. 